\title{
A Practical Fluorescence-Based Screening Protocol for Polyethylene Terephthalate Degrading Microorganisms
}

\author{
Michel R. B. Chaves, ${ }^{a}$ Maria L. S. O. Lima, ${ }^{a}$ Lusiane Malafatti-Picca, ${ }^{b}$ \\ Derlene A. de Angelis, ${ }^{c}$ Aline M. de Castro, ${ }^{d}$ Érika Valoni ${ }^{d}$ and Anita J. Marsaioli ${ }^{*, a}$ \\ Instituto de Química, Universidade Estadual de Campinas, \\ PO Box 6154, 13084-971 Campinas-SP, Brazil \\ ${ }^{b}$ Centro de Estudos Ambientais, Universidade Estadual Paulista (Unesp), \\ Av. 24 A, 1515, 13506-900 Rio Claro-SP, Brazil
}

'Divisão de Recursos Microbianos, Centro Pluridisciplinar de Pesquisas Químicas, Biológicas e Agrícolas (CPQBA), Universidade Estadual de Campinas, Rua Alexandre Cazellato, 999, 13148-218 Paulínia-SP, Brazil

${ }^{d}$ Departamento de Biotecnologia, Centro R\&D, Petrobras, Av. Horácio Macedo, 950, Ilha do Fundão, 21941-915 Rio de Janeiro-RJ, Brazil

\begin{abstract}
We propose a practical, low-cost and selective fluorescence-based protocol adapted to identify polyethylene terephthalate (PET) degrading microorganisms. The microbial hydrolysis of PET nanoparticles was monitored by 2-hydroxyterephthalate, a fluorophore produced in situ after radical hydroxylation of terephthalic acid (TPA), the final hydrolysis product, by the Fenton reaction. Seven fungi presenting promising PET hydrolytic potential using the proposed microscale screening assay were identified. The strains evaluated presented a substantial increase of up to 18-fold in PET nanoparticles conversion, such as obtained by the fungus Trichoderma sp. C70, after their cultivation in a PET-enriched medium. The formation of other hydrolysis products, along with TPA, was observed using matrix assisted laser desorption/ionization-time of flight mass spectrometry (MALDI-TOF MS).
\end{abstract}

Keywords: biocatalysis, Fenton reaction, fluorescence, microorganism screening, PET degradation

\section{Introduction}

The demand for plastic polymers with desirable properties has increased worldwide, along with a rise in environmental polymer accumulation. ${ }^{1}$ The persistence of plastic polymers such as aliphatic polymers in the environment is attributed to the lack of enzymes capable of degrading their rigid structures and can be even more pronounced in the case of aromatic polymers. ${ }^{2,3}$

Polyethylene terephthalate (PET) is an aromatic polyester widely used to make beverage bottles, films and textile fibers, owing to its excellent mechanical strength, high chemical resistance and low gas permeability. ${ }^{4}$ These properties, along with its competitive price, have made PET the most widely produced polyester and the most commonly

*e-mail: anita@iqm.unicamp.br used synthetic fiber, with 56 million metric tons produced in 2013. Increased production and disposal of PET has led to large amounts of the polymer and its oligomers in the environment, composed primarily of terephthalic acid (TPA) and ethylene glycol (EG) monomers. ${ }^{5}$

One strategy to overcome the dependence of polymer production on non-renewable sources is to recycle the monomers. Some of these methods, such as chemical recycling, are energy consuming, cost-intensive and require scaled degradation methods, while others, such as alkaline hydrolysis, may lead to loss of the original material. ${ }^{6}$

The enzymatic hydrolysis of PET is an environmentally friendly alternative to conventional recycling methods and can be performed under milder temperature and $\mathrm{pH}$ conditions, allowing less energy consumption. ${ }^{7}$ Hydrolytic activity against PET has been identified in filamentous fungi, such as Fusarium oxysporum and Fusarium 
solani ${ }^{8}$ and in bacteria from the genus Thermobifida, ${ }^{9}$ with enzymes such as cutinases (EC 3.1.1.74), lipases (EC 3.1.1.3), and carboxylesterases (EC 3.1.1.1) involved in PET degradation. ${ }^{4}$

This is usually monitored by high-performance liquid chromatography (HPLC), which separates monomeric TPA from its ethylene glycol esters, namely mono(2-hydroxyethyl) terephthalate (MHET) and bis-(2-hydroxyethyl) terephthalate (BHET), among other hydrolysis products. Additionally, a number of approaches to evaluate the extent of biodegradation have been used, including turbidimetric analysis,${ }^{10}$ titration, ${ }^{11}$ image scanning, ${ }^{12}$ and polymer film weight loss monitoring. ${ }^{7}$ Fluorometric TPA detection has also been used to monitor PET degradation, but only for isolated enzymes. ${ }^{8,13}$ The high sensitivity of these fluorometric methods allows the assay to be performed with low concentrations of both substrate and biocatalyst (isolated enzymes or whole-cell microorganisms), ensuring a low-cost for the screening without loss of performance. Identifying similar efficient screening methodologies for these enzymes is important for microorganism assays, in order to broaden the search for biocatalysts capable of depolymerizing (or degrading) PET.

Screening methods for whole-cell microorganisms with the potential to hydrolyze PET are usually performed as qualitative assays using agar plates, allowing visual detection of enzymatic activity. These screening techniques use tributyrin or the PET model substrate bis(benzoyloxyethyl) terephthalate (3PET) as supplement in different media, with the presence of clear halos around the colonies indicating the hydrolysis potential of PET. ${ }^{14}$

Currently, PET degradation assays are normally applied to isolated enzymes; however, fast microbial screening methodologies are required in order to discover novel PET degrading enzymes. As such, we propose a rapid and low-cost practical microscale screening methodology to identify microorganisms that express enzymes capable of hydrolyzing PET polymer chains. In the present screening method, whole-cell microorganisms can be tested and lead to the discovery of enzymes with excellent potential to depolymerize PET by selectively detecting the TPA monomer using an adapted Fenton reaction, eliminating the need to separate the hydrolysis products.

\section{Experimental}

\section{General methods}

The strains evaluated were from our private culture collection and were stored on both agar plates and in glycerol solution $(20 \%)$ at $-80{ }^{\circ} \mathrm{C}$. All microorganisms were cultivated in Petri dishes with the appropriate culture medium and, for the induction of PET-degrading enzymes in the microorganisms, it was added PET bottle pieces $(1 \times 1 \mathrm{~cm})$ sterilized with $70 \%$ alcohol and dried in a laminar UV flow hood, according to the procedure described below. The bacteria Bacillus sp. B01, Bacillus sp. B01B, Bacillus sp. B02, Bacillus halodurans B03, Bacillus subtilis B04 and B. subtilis B05 strains (Table 1) were cultivated in NA (nutrient agar, $28 \mathrm{~g} \mathrm{~L}^{-1}$ ). Tryptic soy $\operatorname{agar}\left(30 \mathrm{~g} \mathrm{~L}^{-1}\right.$, Oxoid) was used for the Bacillus okuhidensis B06, Bacillus sp. B07, B. okuhidensis B08, B. okuhidensis B09 and Bacillus pumilus B10 strains. Yeast-maltoseglucose medium, prepared with glucose $\left(4 \mathrm{~g} \mathrm{~L}^{-1}\right.$, Synth), yeast extract $\left(4 \mathrm{~g} \mathrm{~L}^{-1}\right.$, Difco), malt extract $\left(10 \mathrm{~g} \mathrm{~L}^{-1}\right.$, Oxoid), $\mathrm{CaCO}_{3}\left(2 \mathrm{~g} \mathrm{~L}^{-1}\right.$, Cinética Química), agar (12 $\mathrm{g} \mathrm{L}^{-1}$, Oxoid) and $1.5 \% \mathrm{NaCl}(\mathrm{m} / \mathrm{v}$, Synth), was used to cultivate Bacillus sp. B11. The yeasts were cultivated in Sabouraud medium, containing glucose $\left(40 \mathrm{~g} \mathrm{~L}^{-1}\right)$, peptone $\left(40 \mathrm{~g} \mathrm{~L}^{-1}\right.$, Difco) and agar (15 $\left.\mathrm{g} \mathrm{L}^{-1}\right)$, while the fungi from this library were cultivated in potato dextrose agar $\left(39 \mathrm{~g} \mathrm{~L}^{-1}\right.$, Difco) medium, except for the fungi Neopestalotiopsis sp. F053 and E. sorghinum F061, which were incubated in malt extract agar $\left(50 \mathrm{~g} \mathrm{~L}^{-1}\right.$, Oxoid). Bacteria and yeasts were cultivated for $24 \mathrm{~h}$ at $30^{\circ} \mathrm{C}$, while fungi were cultivated for 7 days at $30^{\circ} \mathrm{C}$. After growth, cell masses were weighed and suspended in borate buffer $(20 \mathrm{mM}, \mathrm{pH} 7.8)$ and immediately used.

PET polymer was acquired from commercial, non-carbonated mineral water bottles $\left(\right.$ Bonafont $\left.^{\odot}\right)$ and was used as nanoparticles, prepared from $1 \times 1 \mathrm{~cm}$ pieces of PET bottle, according to Welzel et al. ${ }^{15}$ TPA, BHET, ethylenediaminetetraacetic acid (EDTA), $\mathrm{FeSO}_{4} \cdot 7 \mathrm{H}_{2} \mathrm{O}$, $\mathrm{H}_{2} \mathrm{O}_{2}$ and other standard chemicals were purchased from Sigma-Aldrich (Steinheim, Germany). MHET was obtained from the controlled enzymatic hydrolysis of BHET using conditions reported by Carniel et al. ${ }^{16}$

\section{Enzymatic PET degradation assays}

All assays were performed in 96-well black microtiter plates (with $200 \mu \mathrm{L}$ in each well) and incubated at $28^{\circ} \mathrm{C}$ and $200 \mathrm{rpm}$, until fluorescence reading was performed. These assays (enzymatic assays, negative controls, positive controls and microbial control) were monitored simultaneously, according to 2-hydroxyterephthalate (HOTP, $\lambda_{\mathrm{ex}}=328 \mathrm{~nm}$ and $\lambda_{\mathrm{em}}=421 \mathrm{~nm}$ ) wavelengths in 2300 EnSpireTM Multimodal Reader (PerkinElmer). The monitoring of the fluorescence assay was performed by adding $\mathrm{H}_{2} \mathrm{O}_{2}$, EDTA, and $\mathrm{FeSO}_{4} \cdot 7 \mathrm{H}_{2} \mathrm{O}$ before each analysis to trigger HOTP formation. This assays were monitored every 5 days for 15 days. All assays were 
prepared in triplicate and simultaneously run with positive and negative controls, both in duplicate, together with a microbial control.

\section{Enzymatic assay}

In each well, PET nanoparticles solution $(30 \mu \mathrm{L}$, $\left.0.11 \mathrm{mg} \mathrm{mL}^{-1}\right)$ was added as the substrate and microbial suspension $\left(100 \mu \mathrm{L}, 0.2 \mathrm{mg} \mathrm{mL}^{-1}\right.$ for bacteria and yeasts and $1 \mathrm{mg} \mathrm{mL}^{-1}$ for fungi) in borate buffer $(20 \mathrm{mM}) \mathrm{pH} 7.8$. Before performing fluorescence readings, and to complete the $200 \mu \mathrm{L}$ in the well, $\mathrm{H}_{2} \mathrm{O}_{2}(30 \mu \mathrm{L}, 2 \% \mathrm{v} / \mathrm{v})$, EDTA $(20 \mu \mathrm{L}$, $3 \mathrm{mM}$ ) and $\mathrm{FeSO}_{4} \cdot 7 \mathrm{H}_{2} \mathrm{O}(20 \mu \mathrm{L}, 3 \mathrm{mM})$ (in this order) were added and the microplate was incubated for $25 \mathrm{~min}$ at room temperature to trigger HOTP formation.

\section{Positive control}

In each well, terephthalic acid $(30 \mu \mathrm{L}, 2.6 \mathrm{mM})$ was added as the substrate and microbial suspension $(100 \mu \mathrm{L}$, $0.2 \mathrm{mg} \mathrm{mL}^{-1}$ for bacteria and yeasts and $1 \mathrm{mg} \mathrm{mL}^{-1}$ for fungi) in borate buffer $(20 \mathrm{mM}) \mathrm{pH} 7.8$, to determine the maximum fluorescence intensity. Before performing fluorescence readings, and to complete the $200 \mu \mathrm{L}$ in the well, $\mathrm{H}_{2} \mathrm{O}_{2}(30 \mu \mathrm{L}, 2 \% \mathrm{v} / \mathrm{v})$, EDTA $(20 \mu \mathrm{L}, 3 \mathrm{mM})$ and $\mathrm{FeSO}_{4} .7 \mathrm{H}_{2} \mathrm{O}(20 \mu \mathrm{L}, 3 \mathrm{mM})$ (in this order) were added and the microplate was incubated for $25 \mathrm{~min}$ at room temperature to trigger HOTP formation.

\section{Negative control}

In each well, it was added PET nanoparticles ( $30 \mu \mathrm{L}$, $\left.0.11 \mathrm{mg} \mathrm{mL}^{-1}\right)$ and borate buffer $(100 \mu \mathrm{L}, 20 \mathrm{mM}) \mathrm{pH} 7.8$, to evaluate spontaneous nanoparticle hydrolysis. Before performing fluorescence readings, and to complete the $200 \mu \mathrm{L}$ in the well, $\mathrm{H}_{2} \mathrm{O}_{2}(30 \mu \mathrm{L}, 2 \% \mathrm{v} / \mathrm{v})$, EDTA $(20 \mu \mathrm{L}$, $3 \mathrm{mM}$ ) and $\mathrm{FeSO}_{4} \cdot 7 \mathrm{H}_{2} \mathrm{O}(20 \mu \mathrm{L}, 3 \mathrm{mM})$ (in this order) were added and the microplate was incubated for $25 \mathrm{~min}$ at room temperature to trigger HOTP formation.

\section{Microbial control}

In each well, microbial suspension $(100 \mu \mathrm{L})$ and borate buffer $(30 \mu \mathrm{L}, 20 \mathrm{mM})$ were added to exclude microorganism background fluorescence. Before performing fluorescence readings, and to complete the $200 \mu \mathrm{L}$ in the well, $\mathrm{H}_{2} \mathrm{O}_{2}$ $(30 \mu \mathrm{L}, 2 \% \mathrm{v} / \mathrm{v})$, EDTA $(20 \mu \mathrm{L}, 3 \mathrm{mM})$ and $\mathrm{FeSO}_{4} \cdot 7 \mathrm{H}_{2} \mathrm{O}$ $(20 \mu \mathrm{L}, 3 \mathrm{mM})$ (in this order) were added and the microplate was incubated for $25 \mathrm{~min}$ at room temperature to trigger HOTP formation.

The conversions were obtained according to equation 1 . Fluorescence analyses were conducted at $421 \mathrm{~nm}$ (excitation wavelength: $328 \mathrm{~nm}$ ) in a 2300 EnSpire Multimodal Reader (PerkinElmer).

$\mathrm{c} \%=\left(\frac{\left(\begin{array}{c}\text { mean fluoresc. } \\ \text { assay }\end{array}\right)-\left(\begin{array}{c}\text { mean fluoresc. } \\ \text { neg. contr. }\end{array}\right)-\left(\begin{array}{c}\text { mean fluoresc. } \\ \text { microb. contr. }\end{array}\right)}{\text { mean fluoresc. pos. contr. }}\right) \times 100$

\section{Scanning electron microscopy (SEM) imaging}

PET nanoparticle sizes were determined by SEM in an FEI Quanta FEG 250 at an accelerating voltage of $10 \mathrm{kV}$. Samples were previously coated with gold in an argon field using a Baltec MED 020 Coating System for $100 \mathrm{~s}$ at $11.3 \mathrm{~mA}$. Digitized images were processed using ImageJ software. ${ }^{17}$

\section{Induction of PET-degrading enzymes}

The microorganisms were cultivated following the same conditions described for the PET degradation experiments (growing in their correspondent medium at $30{ }^{\circ} \mathrm{C}$ for $24 \mathrm{~h}$, for bacteria and yeasts, and $48 \mathrm{~h}$, for fungi), but supplemented with $1.5 \%(\mathrm{~m} / \mathrm{v})$ PET bottle pieces $(1 \times 1 \mathrm{~cm})$ sterilized with $70 \%$ alcohol and dried in a laminar UV flow hood. The strains cultivated on PET enriched medium were defined as first-generation strains. These strains were inoculated once again onto fresh PET-enriched medium in the same previous conditions to obtain so-called second-generation of PET degrading strains, as described in the Scheme 1. The new strains were submitted to the fluorescence-based PET degrading assay to evaluate their increase in the polymer conversion.

The morphological characteristics of the strains were monitored during cultivation and showed no morphology

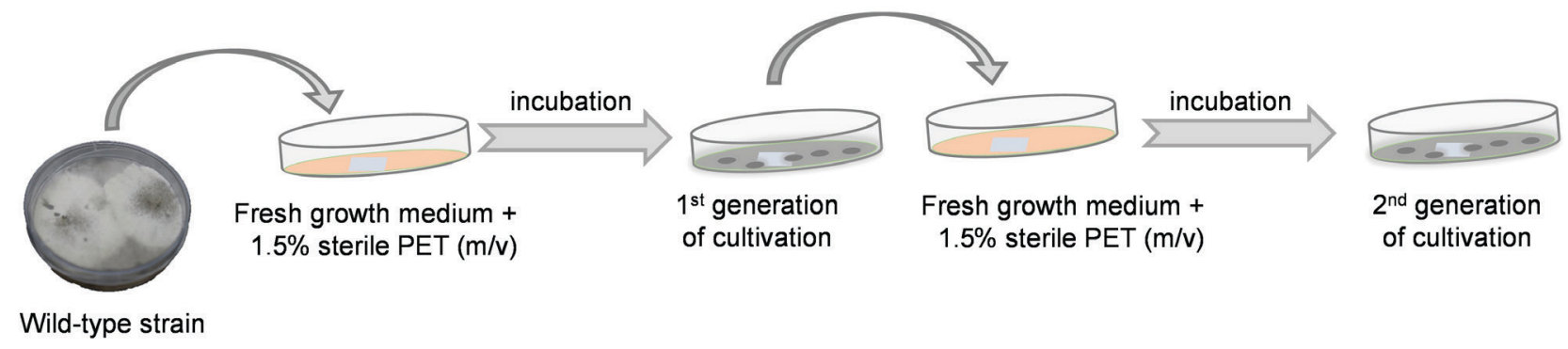

Scheme 1. Schematic illustration of the cultivation of the strains in PET-enriched medium to induce the expression of PET degrading enzymes. 
alterations, ensuring the identity of each of the inoculated strains during cultivation with PET pieces.

Matrix assisted laser desorption/ionization-time of flight mass spectrometry (MALDI-TOF MS) analysis

Analyses were carried out on a MALDI-TOF Bruker Microflex LT mass spectrometer in positive linear mode, with a laser frequency of $60 \mathrm{~Hz}$, ion source 1 at a voltage of $10.03 \mathrm{~V}$, ion source 2 at a voltage of $9.1 \mathrm{~V}$, voltage lenses of $6 \mathrm{~V}$ and a mass range of 150 to $410 \mathrm{Da}$. The final spectra obtained represent a combination of 500 spectra acquired from different positions within the sample well. Monitoring consisted of applying $2 \mu \mathrm{L}$ of the reaction medium from the PET degradation assay in a polished steel plate, followed by overlaying with the same amount of matrix $\alpha$-cyano-4-hydroxycinnamic acid $\left(10 \mathrm{mg} \mathrm{mL}^{-1}\right)$ (CHCA, Sigma-Aldrich, São Paulo, Brazil) dissolved in acetonitrile/water/2.5\% trifluoroacetic acid 50:47.5:2.5. Standard compounds BHET and MHET were used for calibration before analysis.

\section{Results and Discussion}

The microorganisms were evaluated during PET microbial hydrolysis for the release of the TPA monomer. Once TPA (2) is produced, it undergoes radical hydroxylation in the presence of $\mathrm{H}_{2} \mathrm{O}_{2}$-Fe - II-EDTA (Fenton reaction), leading to the formation of fluorescent HOTP (3) (Scheme 2), thereby allowing fluorometric monitoring of polyester biodegradation. The Fenton reaction is considered one of the simplest laboratory-scale reactions for ${ }^{\circ} \mathrm{OH}$ production and is readily applicable to in vivo fluorometric methodologies for ${ }^{\circ} \mathrm{OH}$ scavenging. ${ }^{18}$

The symmetrical structure of the terephthalate ion (2) means radical hydroxylation only produces mono ortho-hydroxylated HOTP isomer (3), whose fluorescence is stable for up to $36 \mathrm{~h} .{ }^{19}$ The excitation and emission spectra of the product, recorded in borate buffer solution $(\mathrm{pH}=7.8)$, showed the same excitation (data not shown) and emission wavelengths (Figure 1) as an HOTP standard solution.

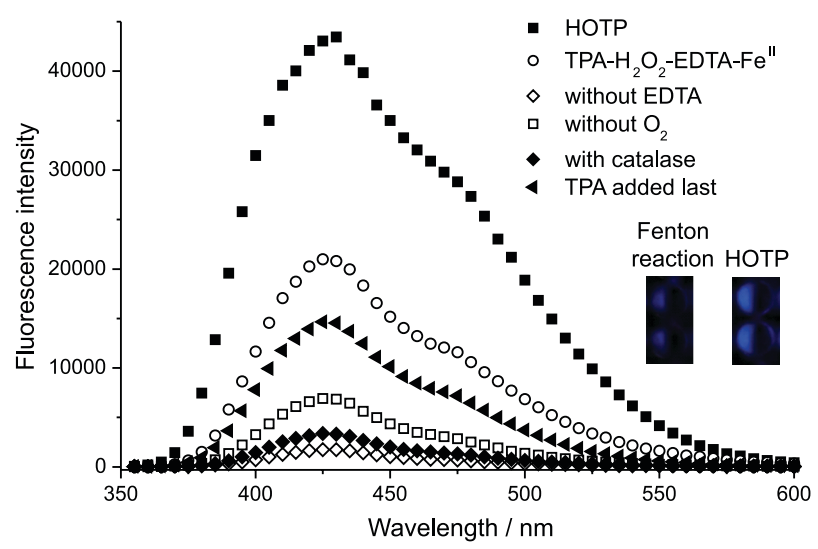

Figure 1. Fluorescence emission spectra of standard HOTP $(\boldsymbol{\square}, 0.5 \mathrm{mM}$, in $0.1 \mathrm{M} \mathrm{NaOH})$; $(\bigcirc)$ TPA- $\mathrm{H}_{2} \mathrm{O}_{2}$-EDTA-Fe ${ }^{\mathrm{II}}$ system; $(\diamond)$ removal of EDTA; $(\square)$ with deoxygenation of the solution by $\mathrm{N}_{2}$ for 10 min before the addition of $\mathrm{Fe}^{\mathrm{II}}$; $(\bullet)$ addition of $10 \mu \mathrm{L}$ of $100 \mathrm{U} \mathrm{mg}^{-1}$ catalase before the addition of $\mathrm{Fe}^{\mathrm{II}} ;(-)$ addition of TPA after $\mathrm{H}_{2} \mathrm{O}_{2}$, EDTA and $\mathrm{Fe}^{\mathrm{II}}$. The insert compares the fluorescence resulting from Fenton reaction and the standard HOTP under $354 \mathrm{~nm}$ UV light.

The main step for the formation of fluorescent HOTP is the presence of reactive oxygen species; thus, experiments were conducted to understand the role of ${ }^{\circ} \mathrm{OH}$ generated from hydrogen peroxide. Initially, the comparison of fluorescent signals of the Fenton reaction and standard HOTP solution revealed incomplete conversion of TPA into HOTP ( $48 \%$ conversion), as previously reported. ${ }^{20}$ This incomplete conversion is also evident in the fluorescence observed in microtiter wells (Figure 1).

The reaction medium was also flushed with $\mathrm{N}_{2}$ for $10 \mathrm{~min}$ before the addition of iron(II) in order to investigate the influence of dissolved oxygen on radical formation. The resulting emission spectra showed a sharp decrease in intensity, highlighting the role of oxygen in ${ }^{\circ} \mathrm{OH}$ formation.

Microbial hydrogen peroxide degradation during the Fenton reaction was also investigated, since the catalase expressed by some microorganisms can interfere in HOTP

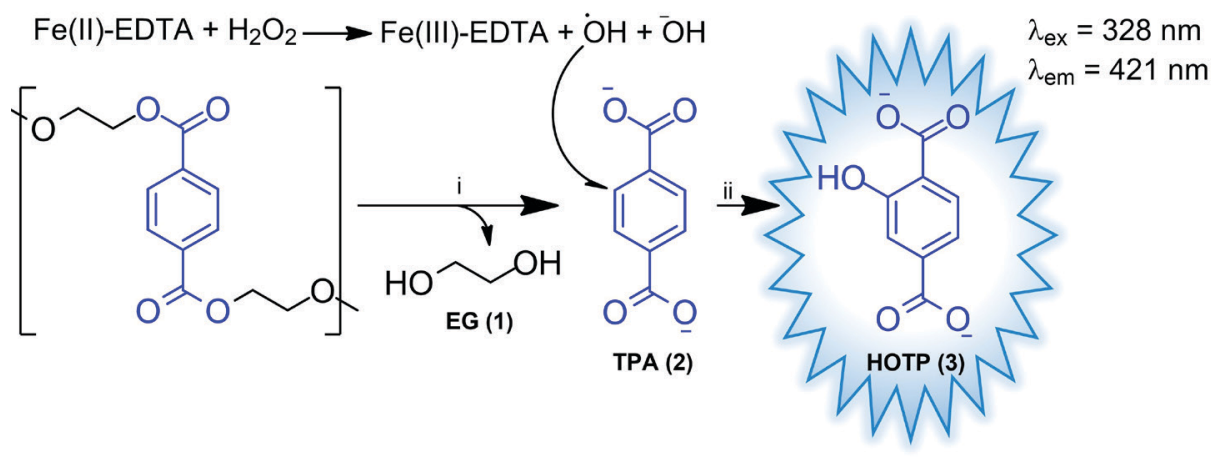

Scheme 2. PET enzymatic hydrolysis ( $i$ ) followed by radical hydroxylation of released TPA (2), (ii) furnishing the fluorescent HOTP (3). 
production. The addition of catalase to the medium before iron(II) caused a significant decrease in the fluorescence signal. Additionally, the removal of EDTA caused a decline in HOTP formation, demonstrating the catalytic activity of the $\mathrm{Fe}^{\mathrm{II}}$-EDTA complex. When TPA was added after $\mathrm{H}_{2} \mathrm{O}_{2}$, EDTA and $\mathrm{Fe}^{\mathrm{II}}$, in this order, the fluorescence signal was lower than that obtained by adding TPA first. This may be attributed to the decay of ${ }^{\circ} \mathrm{OH}$, produced during the Fenton reaction, before hydroxylation occurs, which accounts for the decrease in HOTP. ${ }^{21}$

The previous method to produce HOTP from TPA with hydrogen peroxide required a reaction temperature of $90^{\circ} \mathrm{C}$, which can cause the formation of bubbles and jeopardize fluorometric analysis. ${ }^{22}$ The method presented here was performed at $30{ }^{\circ} \mathrm{C}$ and showed a linear dependence from 150 to $500 \mu \mathrm{M}$, making it suitable for the proposed assay (see Figure S2, Supplementary Information (SI) section).

Once all conditions were established, the screening assays for microbial hydrolysis were conducted accordingly, using PET nanoparticles as substrates. The nanoparticles were prepared using a precipitation method ${ }^{15}$ and characterized by scanning electron microscopy (SEM), displaying particle sizes ranging 40-70 nm (see Figure S1, SI section).

Enzymatic polymer degradation is governed by surface erosion, since the larger enzyme size precludes penetration into polymer interstices. Thus, the enzymatic polymer hydrolysis rate can be improved when the process is conducted with nanoparticles, which exhibit an enhanced surface area when compared to polymer films. ${ }^{11,23}$ This higher hydrolysis rate provided by the enhanced surface area can overcome the limitation caused by the densely packed structure of PET bottles, resulting in greater enzyme access to PET polyester chains. ${ }^{4}$

The fungus Aspergillus oryzae C361 showed one of the highest conversions of PET nanoparticles (Table 1). Similar potential of the this fungus to hydrolyze PET was also investigated by Wang et al. ${ }^{24}$ by applying an extracellular lipase to promote a modification (hydrolysis) in the PET fabric.

Table 1. PET nanoparticle microbial conversions detected by fluorescence after 15 days

\begin{tabular}{|c|c|c|c|c|c|}
\hline Code & Identification & Conversion $^{\mathrm{a}} / \%$ & Code & Identification & Conversion $^{\mathrm{a}} / \%$ \\
\hline \multicolumn{6}{|c|}{ Bacteria } \\
\hline B01 & Bacillus sp. & $0.0 \pm 0.0$ & B06 & B. okuhidensis & $0.5 \pm 0.2$ \\
\hline В01B & Bacillus sp. & $0.0 \pm 0.0$ & B08 & B. okuhidensis & $0.1 \pm 0.0$ \\
\hline B02 & Bacillus sp. & $0.0 \pm 0.0$ & B09 & B. halodurans & $0.3 \pm 0.1$ \\
\hline B03 & B. halodurans & $0.2 \pm 0.0$ & B10 & B. pumilus & $0.4 \pm 0.1$ \\
\hline B04 & B. subtilis & $0.1 \pm 0.0$ & B11 & Bacillus sp. & $0.4 \pm 0.1$ \\
\hline B05 & B. subtilis & $0.3 \pm 0.1$ & & & \\
\hline \multicolumn{6}{|l|}{ Yeast } \\
\hline C32 & C. viswanathii & $0.0 \pm 0.0$ & C129 & C. viswanathii & $0.2 \pm 0.0$ \\
\hline C17 & C. viswanathii & $0.1 \pm 0.0$ & C19 & C. viswanathii & $0.4 \pm 0.0$ \\
\hline $\mathrm{C} 20$ & C. viswanathii & $0.1 \pm 0.1$ & $\mathrm{C} 21$ & C. viswanathii & $0.4 \pm 0.2$ \\
\hline C36 & C. viswanathii & $0.1 \pm 0.0$ & $\mathrm{C} 33$ & C. viswanathii & $0.4 \pm 0.1$ \\
\hline C127 & C. viswanathii & $0.1 \pm 0.0$ & $\mathrm{C} 16$ & C. viswanathii & $0.5 \pm 0.1$ \\
\hline C133 & C. viswanathii & $0.1 \pm 0.1$ & C49 & C. viswanathii & $0.6 \pm 0.1$ \\
\hline C96 & C. viswanathii & $0.2 \pm 0.1$ & $\mathrm{C} 62$ & S. cerevisiae & $0.1 \pm 0.1$ \\
\hline \multicolumn{6}{|l|}{ Fungi } \\
\hline C357 & R. miehei & $0.3 \pm 0.1$ & $\mathrm{C} 70$ & Trichoderma sp. & $0.2 \pm 0.0$ \\
\hline C360 & P. brevicompactum & $0.2 \pm 0.1$ & L1239 & Trichoderma sp. & $7.1 \pm 0.2$ \\
\hline C361 & A. oryzae & $1.0 \pm 0.1$ & F053 & Neopestalotiopsis sp. & $0.4 \pm 0.1$ \\
\hline C362 & Aspergillus sp. & $0.1 \pm 0.0$ & F057 & E. sorghinum & $0.5 \pm 0.1$ \\
\hline C363 & Aspergillus sp. & $0.4 \pm 0.1$ & L43 & M. arundinis & $2.4 \pm 0.4$ \\
\hline C64 & Trichoderma sp. & $0.4 \pm 0.1$ & L84 & M. arundinis & $4.1 \pm 0.5$ \\
\hline C65 & Trichoderma sp. & $1.7 \pm 0.3$ & L1269 & Fusarium sp. & $1.4 \pm 0.2$ \\
\hline C68 & Trichoderma sp. & $1.1 \pm 0.2$ & & & \\
\hline
\end{tabular}

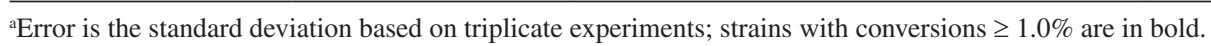


The fungi C65, C68 and L1239, belonging to the genus Trichoderma sp., showed PET nanoparticle conversions of $1.7,1.1$ and $7.1 \%$, respectively (Table 1), where the latter can be referred as the most promising strain to depolymerize PET among the microorganisms screened.

The fungus Fusarium sp., known as a plant pathogen, has proven to be a reliable source for PET degrading cutinases, likely for the same reasons as fungi from the Aspergillus and Trichoderma genus. ${ }^{8,25}$ This corroborates the result obtained for the Fusarium sp. L1269 strain, capable of hydrolyzing PET nanoparticle with $1.4 \%$ conversion.

Fungal strains $M$. arundinis L43 and L84 also presented noticeable results for PET conversion. A plausible explanation for this outcome is the saprobiontic (or parasitic) behavior of the fungus from these species in plants. ${ }^{26}$ During infection of the plant host, the fungus hydrolyzes cutin, a polyester network containing hydroxylfatty acids that forms the cuticle on the epidermal cell wall of the plant. ${ }^{27}$ The ability of cutinases to degrade this natural polyester has prompted their use in industrial applications in reactions with synthetic polymers, such as PET. ${ }^{6,25}$

In an attempt to achieve higher microbial conversions of the polymer substrate, some of the fungi with promising results in PET nanoparticles, along with other presenting moderate results, were cultivated in a PET-enriched medium to induce the expression of hydrolytic enzymes and enhance their biodegradation potential for this substrate (Figure 2). ${ }^{24,28}$ Surprisingly, the efficient strains A. oryzae C361, Trichoderma sp. C65 and Trichoderma sp. C68 showed no increase in PET biodegradation using this cultivation procedure. By contrast, other strains with much lower conversions, such as Trichoderma sp. C70 and $R$. miehei $\mathrm{C} 357$, exhibited higher hydrolytic enzyme induction when cultivated in PET-enriched medium.

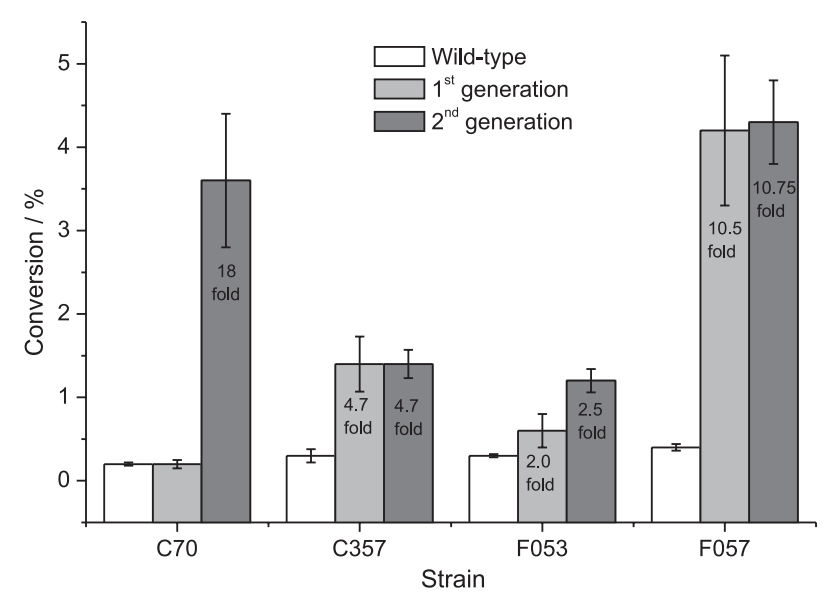

Figure 2. Graphic depiction for the conversions improvement (\%) obtained by fluorescence after successive generations of the fungi cultivated in PET-enriched medium compared to their wild-type strains.
The same behavior than the last mentioned strains was observed for the fungus Neopestalotiopsis sp. F053, with $0.4 \%$ conversion for the wild-type strain and an increased conversion of $1.5 \%$ after two generations of PET-enriched cultivation, and the E. sorghinun F057 strain, with a more pronounced outcome of $4.3 \%$ PET conversion into TPA, almost 11-fold greater than the wild-type fungus result.

The strains Trichoderma sp. C70 and R. miehei C357 also showed a remarkable polymer conversion rate improvement of 18 fold and 4.7 fold higher, respectively, when compared to their wild-type strain after cultivation with PET pieces (Figure 2). The fungal strains M. arundinis L43 and L84, Trichoderma sp. L1239 and Fusarium sp. 1269 are currently under further investigation for the induction of PET degrading enzymes.

A comparable result was observed by Gouda et al. ${ }^{29}$ when a polyester-degrading hydrolase was only produced in the presence of a BTA copolyester (1,4-butanediol, terephthalic acid and adipic acid; around 40-50 mol\% terephthalic acid in the acid component). A previous similar approach to induce PET degrading enzymes resulted in $34 \%$ increase in lipase activity when BHET was used as the inducer, but was lower (4\%) when a PET short fiber was used..$^{24}$ This suggests that the strains exhibit different responses to the inducer used, explaining the range (or absence) of enhanced conversions observed.

The Trichoderma sp. C70 strain assay (second generation grown in PET-enriched medium) was analyzed by MALDI-TOF MS after 15 days and showed the presence of the intermediate MHET (4), highlighted by both $\mathrm{m} / \mathrm{z}$ peak 210.905 and the sodium adduct $[\mathrm{M}+\mathrm{Na}]^{+}$in $\mathrm{m} / z$ 233.030, evident in the mass spectra (Figure 3). TPA (2) was also detected in $\mathrm{m} / \mathrm{z}$ peak 166.920 in the mass spectra, while $\mathrm{m} / \mathrm{z}$ peak 402.332 can be referred to as the hydrolysis product 1,2-ethylene-mono-terephthalate-mono(2-hydroxyethyl) terephthalate (EMT, 5).

The intermediate BHET diester is absent in the spectra obtained, indicating its faster consumption when compared to MHET, as demonstrated by the abundant peaks of the latter intermediate. The mono-ester MHET is known to act as an enzyme inhibitor during the PET enzymatic degradation, causing an accumulation of considerable amounts of this intermediate, ${ }^{16,30}$ as evidenced by intense associated peaks in the spectra.

It is important to emphasize that the presence of TPA indicates that enzymatic hydrolysis was responsible for cleaving the polymer chain, producing intermediates that are further hydrolyzed to TPA, which is detected fluorometrically. This feature can also be promptly evaluated by MALDI-TOF analysis, depicting the relative 


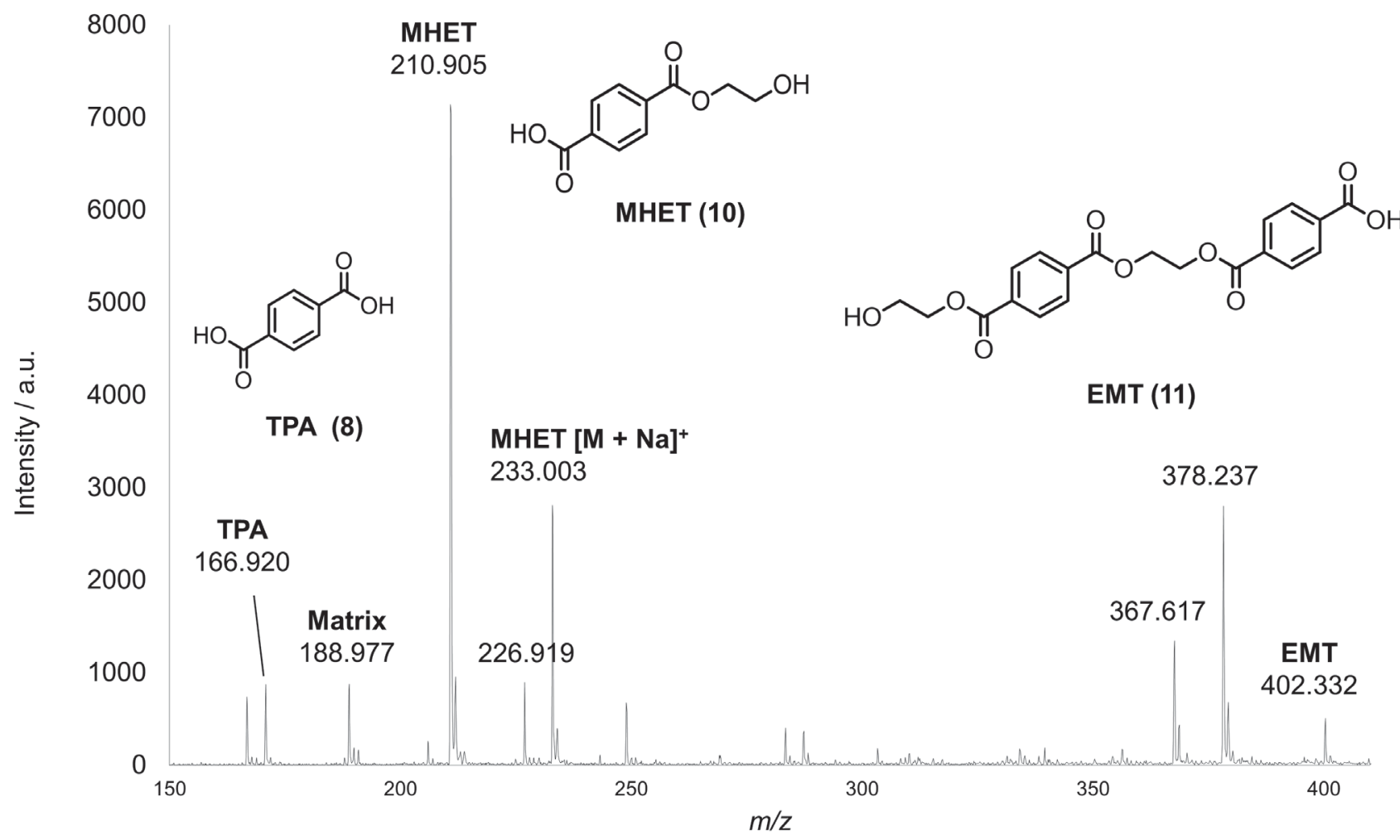

Figure 3. MALDI-TOF MS spectrum of the reaction medium for the second generation of the fungus Trichoderma sp. C70 after 15 days, detailing the peaks for hydrolysis products TPA, MHET and EMT.

intensity between these intermediates and TPA, as discussed earlier for MHET accumulation.

The promising fungal strains A. oryzae C361, Trichoderma sp. C65, C68, C70 and Neopestalotiopsis sp. F053 were deposited in the Brazilian Collection of Microorganisms from Environment and Industry (CBMAI) under identification codes CBMAI 2034, CBMAI 1932, CBMAI 2032, CBMAI 2033 and CBMAI 2030, respectively. The fungi $R$. miehei $\mathrm{C} 357$, E. sorghinum $\mathrm{F} 057$, M. arundinis L43 and L84, Trichoderma sp. L1269 and L1239 are in the process of being deposited in the same collection.

\section{Conclusions}

The practical, low-cost fluorescence screening method proposed here was successfully adapted to screening PET degrading microorganisms. Polymer nanoparticles applied using the Fenton reaction allowed the methodology to be applied to a large number of strains. Among the strains tested, four fungi presented their PET hydrolysis activities improved when submitted to the induction experiments, which proved to be an effective procedure for obtaining microorganisms with enhanced potential to degrade PET when compared to the respective wild-type strain. MALDI-TOF analysis combined with fluorometric monitoring of enzymatic PET degradation rapidly provided important complementary information, such as accumulation of one of the hydrolysis intermediates produced. Finally, the fast, green methodologies applied here may help future screening for environmental PET degrading microorganisms, with either wild type strains, induction of enzymatic activities, directed evolution experiments or directed mutagenesis.

\section{Supplementary Information}

Supplementary information (calibration curve for the Fenton reaction and SEM image for the nanoparticles) is available free of charge at http://jbcs.sbq.org.br as PDF file.

\section{Acknowledgments}

The authors thank PETROBRAS (grant 2012/00327-7), CNPq (National Research Council, 140741/2013-5 and 307885/2013-5), FAPESP-GSK (2014/50249-8) for grants and financial support and Professor José Augusto Rosário Rodrigues (Institute of Chemistry, Unicamp) for providing the mechanical stirrer used in nanoparticle preparation.

\section{References}

1. Sinha, V.; Patel, M. R.; Patel, J. V.; J. Polym. Environ. 2010, $18,8$. 
2. Kint, D.; Munoz-Guerra, S.; Polym. Int. 1999, 48, 346.

3. Müller, R. J.; Kleeberg, I.; Deckwer, W. D.; J. Biotechnol. 2001, 86,87 .

4. Zimmermann, W.; Billig, S. In Enzymes for the Biofunctionalization of Poly(Ethylene Terephthalate); Nyanhongo, G. S.; Steiner, W.; Gübitz, G. M., eds.; SpringerVerlag: Berlin, Germany, 2011, ch. 5.

5. http://www3.weforum.org/docs/WEF_The_New_Plastics_ Economy.pdf, accessed in November 2017.

6. Costa, C. Z.; Albuquerque, R. C. C.; Brum, M. C.; Castro, A. M.; Quim. Nova 2015, 38, 259.

7. Müller, R. J.; Schrader, H.; Profe, J.; Dresler, K.; Deckwer, W. D.; Macromol. Rapid Commun. 2005, 26, 1400.

8. Nimchua, T.; Punnapayak, H.; Zimmermann, W.; Biotechnol. J. 2007, 2, 361.

9. Herrero Acero, E.; Ribitsch, D.; Dellacher, A.; Zitzenbacher, S.; Marold, A.; Steinkellner, G.; Gruber, K.; Schwab, H.; Guebitz, G. M.; Biotechnol. Bioeng. 2013, 110, 2581.

10. Wei, R.; Oeser, T.; Barth, M.; Weigl, N.; Lübs, A.; SchulzSiegmund, M.; Hacker, M. C.; Zimmermann, W.; J. Mol. Catal. B: Enzym. 2014, 103, 72.

11. Herzog, K.; Müller, R. J.; Deckwer, W. D.; Polym. Degrad. Stab. 2006, 91, 2486.

12. Res, J. M. B.; Sepperumal, U.; Markandan, M.; Natarajan, A.; J. Microbiol. Biotechnol. Res. 2013, 3, 104.

13. Silva, C.; Da, S.; Silva, N.; Matamá, T.; Araújo, R.; Martins, M.; Chen, S.; Chen, J.; Wu, J.; Casal, M.; Cavaco-Paulo, A.; Biotechnol. J. 2011, 6, 1230.

14. Sulaiman, S.; Yamato, S.; Kanaya, E.; Kim, J. J.; Koga, Y.; Takano, K.; Kanaya, S.; Appl. Environ. Microbiol. 2012, 78, 1556.

15. Welzel, K.; Müller, R.-J.; Deckwer, W.-D.; Chem. Ing. Tech. 2002, 74, 1496.
16. Carniel, A.; Valoni, É.; Júnior, J. N.; Gomes, A. C.; Castro, A. M.; Process Biochem. 2017, 59, 84.

17. Abràmoff, M. D.; Magalhães, P. J.; Ram, S. J.; Biophotonics Int. 2004, 11, 36.

18. Yan, E. B.; Unthank, J. K.; Castillo-Melendez, M.; Miller, S. L.; Langford, J.; Walker, D. W.; J. Appl. Physiol. 2005, 98, 2304.

19. Saran, M.; Summer, K. H.; Free Radical Res. 1999, 31, 429.

20. Matthews, R. W.; Radiat. Res. 1980, 83, 27.

21. Yang, X.; Guo, X.; Analyst 2001, 126, 928.

22. O'Neill, A.; Cavaco-Paulo, A.; Biocatal. Biotransform. 2004, 22, 357.

23. Figueroa, Y.; Hinks, D.; Montero, G.; Biotechnol. Progress 2006, 22, 1209.

24. Wang, X.; Lu, D.; Jönsson, L. J.; Hong, F.; Eng. Life Sci. 2008, $8,268$.

25. Baker, J. M.; Montclare, J. K. In Biotransformations Using Cutinase; Pio, T. F.; Macedo, G. A., eds.; Elesvier Inc.: Washington, USA, 2010, ch. 11.

26. Pendle, S.; Weeks, K.; Priest, M.; Gill, A.; Hudson, B.; Kotsiou, G.; Pritchard, R.; J. Clin. Microbiol. 2004, 42, 5315.

27. Pio, T. F.; Macedo, G. A. In Advances in Applied Microbiology, vol. 66; Laskin, A.; Gadd, G.; Sariaslani, S., eds.; Elsevier Inc.: USA, 2009, ch. 4.

28. Costa, J. H.; da Costa, B. Z.; de Angelis, D. A.; Marsaioli, A. J.; Appl. Microbiol. Biotechnol. 2017, 101, 6061.

29. Gouda, M. K.; Kleeberg, I.; Van den Heuvel, J.; Müller, R. J.; Deckwer, W. D.; Biotechnol. Progress 2002, 18, 927.

30. Barth, M.; Oeser, T.; Wei, R.; Then, J.; Schmidt, J.; Zimmermann, W.; Biochem. Eng. J. 2015, 93, 222.

Submitted: October 25, 2017 Published online: December 6, 2017 